\title{
Potential renovascular hypertension, space missions, and the role of magnesium
}

This article was published in the following Dove Press journal: International Journal of Nephrology and Renovascular Disease 18 November 2009

Number of times this article has been viewed

\author{
William J Rowe \\ Former Assistant Clinical Professor \\ of Medicine, Medical University \\ of Ohio at Toledo, Keswick, VA, USA
}

\begin{abstract}
Space flight (SF) and dust inhalation in habitats cause hypertension whereas in SF (alone) there is no consistent hypertension but reduced diurnal blood pressure (BP) variation instead. Current pharmaceutical subcutaneous delivery systems are inadequate and there is impairment in the absorption, metabolism, excretion, and deterioration of some pharmaceuticals. Data obtained from the National Aeronautics and Space Administration through the Freedom of Information Act shows that Irwin returned from his 12-day Apollo 15 mission in 1971 and was administered a bicycle stress test. With just three minutes of exercise, his BP was $>275 / 125 \mathrm{~mm} \mathrm{Hg}$ (heart rate of only 130 beats per minute). There was no acute renal insult. Irwin's apparent spontaneous remission is suggested to be related to the increase of a protective vasodilator, and his atrial natriuretic peptide (ANP) reduced with SF because of reduced plasma volume. With invariable malabsorption and loss of bone/muscle storage sites, there are significant $(P<0.0001)$ reductions of magnesium $(\mathrm{Mg})$ required for ANP synthesis and release. Reductions of $\mathrm{Mg}$ and ANP can trigger pronounced angiotensin (200\%), endothelin, and catecholamine elevations (clearly shown in recent years) and vicious cycles between the latter and $\mathrm{Mg}$ deficits. There is proteinuria, elevated creatinine, and reduced renal concentrating ability with the potential for progressive inflammatory and oxidative stress-induced renal disease and hypertension with vicious cycles. After SF, animals show myocardial endothelial injuries and increased vascular resistance of extremities in humans. Even without dust, hypertension might eventually develop from renovascular hypertension during very long missions. Without sufficient endothelial protection from pharmaceuticals, a comprehensive gene research program should begin now.

Keywords: magnesium, atrial natriuretic peptide, dust, renovascular hypertension, microgravity
\end{abstract}

"The farther backward you can look, the farther forward you are likely to see."

-Winston Churchill

\section{Introduction}

Even without radiation the endothelium is vulnerable to dysfunction/injuries with space flight (SF) because of oxidative stress involving both the cardiovascular system as well as the systemic circulation in the "Apollo 15 space syndrome." This syndrome, which I described, was experienced by both Irwin and Scott on the first of three excursions to the lunar surface, even prior to dust inhalation in that habitat. My syndrome was characterized by very painful, apparently swollen, fingertips possibly secondary to peripheral vasospasm and compression by fluid trapped distally. Therefore it can be a warning that coronary vasospasm with ischemia (possibly silent) might also exist, predisposing the person to a myocardial infarction.
Correspondence: William J Rowe

I 485 Bremerton La, Keswick,

VA 22947, USA

Tel +I 4349840079

Email rowerun@aol.com 
Similarly vasoconstriction of systemic blood vessels could be the underlying mechanism of a decrease of calf blood flow of $40 \%$. Measurements taken between 4-12 SFdays showed calf vascular resistance doubling. The blood pressure (BP) increased during SF. ${ }^{2}$ With SF, vicious cycles can occur between magnesium $(\mathrm{Mg})$ ion deficits and catecholamine elevations and also between catecholamine elevations and ischemia. Furthermore vicious cycles can also develop between reduced nitric oxide (NO), coronary vasospasm with turbulence, and endothelial injuries. ${ }^{3}$

Through information obtained by the Freedom of Information Act (FOIA), I acquired bicycle stress test data regarding Irwin on Apollo 15 showing extraordinary hypertension. The stress test data indicated a BP $>275 / 125 \mathrm{~mm} \mathrm{Hg}$ with a heart rate of only 132 per minute after just three minutes of exercise. This test was probably performed on the day after his return from the 12-day mission. The resting BP was not shown, but at one minute the BP was $250 / 125$, with the same heart rate. There was no evidence of an acute renal insult. On the other hand it is noteworthy that Shepard's bicycle stress test data, on the day after his return from the Apollo 14 mission, revealed a relatively normal response, with a BP of 200/75 at the same heart rate as Irwin's, but not reaching this level (132 per minute) until 13 minutes of exercise.

One mechanism for this discrepancy could be related to the variation in the chemical composition of the dust inhaled at various lunar landing site habitats. ${ }^{4}$ Conrad's stress test data - the only other deceased moon walker (Apollo 12) - is not available, after a "careful search" by National Aeronautics and Space Administration (NASA) in response to my FOIA request in 2008.

On the stress test, on the day of his return, Irwin showed "cyanosis of the finger tips" from the 18th-20th minutes with a BP of 200/90, consistent with venous blood trapped distally, which supports my syndrome on the likelihood of space syndrome. I postulated that the severe hypertension was a complication of dust inhalation. The inhalation had occurred for a total of almost seven days; about 40 hours in the lunar habitat, two days orbiting the moon, making the survey, dust brought into the command module and the threeday journey home. ${ }^{4}$ The vulnerability to endothelial injuries is far greater in males and in addition the endothelium does not heal adequately after the age of 30 years. ${ }^{3}$ Furthermore, assuming that some day the problems of hypertension related to dust, brought from the habitats on the moon, will be resolved with removal of even ultrafine dust, ${ }^{4}$ there are the problems stemming from depletion of the reservoirs for water ie, primarily in skeletal muscle and $\mathrm{Mg}$ reservoirs in muscle and bone (about $60 \%$ in the latter). This loss stems from hypokinesia (decreased movement) compounded by decreased thirst and is conducive to oxidative stress-induced renovascular hypertension. ${ }^{5}$ To prevent this, gene therapy may be necessary ${ }^{6,7}$ since there are multiple problems with pharmaceuticals; there is invariable SF-malabsorption, ${ }^{8}$ deterioration of some medications no longer meeting United States Pharmacopeia (USP) standards ${ }^{9}$ and impairment in pharmaceutical metabolism and excretion because of potential SF injuries to the liver ${ }^{10}$ and kidneys. ${ }^{11}$

Whereas Fritsch-Yelle and colleagues ${ }^{12}$ found reduced BP on shuttle missions of 5-10 days; Shiraishi and colleagues ${ }^{13}$ found that the waking BP was not different from preflight levels. On the other hand Watenpaugh and colleagues ${ }^{2}$ found that SF BP increased in comparison to postflight supine levels and they suggested that premission differences in baseline conditions could account for these discrepancies. However the absence of a significant drop $(<10 \%)$ in nocturnal $\mathrm{BP}^{12,13}$ indicates that those during SF are "nondippers," which portends to renal disease as discussed below.

\section{Potential renovascular hypertension}

There is a predisposition for progressive oxidative stressinduced renal disease $\mathrm{e}^{5}$ intensified by atrial natriuretic peptide (ANP) deficiencies ${ }^{6,14-16}$ with a $>40 \%$ reduction on Spacelab 2 and excessive levels of catecholamines ${ }^{1,3,4,17,18}$ and the combination of endothelin ${ }^{19}$ and significant angiotensin I elevations $(P<0.0001)^{17}$ conducive to sustained renal vasoconstriction. ${ }^{20,21}$

There is a potential synergism regarding endothelin and angiotensin II blockade which has been shown to improve endothelial function. Blockade of both has also been shown to increase renal blood flow in healthy subjects, ${ }^{21}$ but, as emphasized above, pharmaceuticals can not be utilized. Proteinuria, considered an expression of endothelial dysfunction ${ }^{22}$ and a strong predictor of renal disease progression, ${ }^{23-25}$ with stimulation of endothelin expression in renal cells, ${ }^{19}$ was shown after space missions. ${ }^{17,18}$ Proteinuria was more pronounced after prolonged missions but disappeared during the recovery period ${ }^{17}$ possibly related to reductions back to premission catecholamine levels. ${ }^{23} \mathrm{SF}$ reductions of vascular endothelial growth factor (VEGF) from thrombocytopenia with platelet aggregation from endothelial dysfunction ${ }^{26}$ and impaired VEGF expression as a result of SF insulin resistance ${ }^{27}$ would impair capillary repair in damaged glomeruli and contribute to proteinuria. ${ }^{28,29}$ 
Furthermore the reduced diurnal variabilities in blood pressures ("nondipper") as noted previously increases the risk of renal dysfunction. The mechanisms may be related to increased sympathetic nervous system activity and possibly insulin resistance, both of which have been shown with SF. ${ }^{1,3,4,17,30}$ Many cosmonauts have shown higher levels of blood creatinine during and after SF in comparison to their preflight levels, and there is decreased concentrating ability after SF. ${ }^{17}$ It was also found that urine osmolarity in response to fluid deprivation was consistently lower after flight than before, but only if the flight lasted more than 30 days. $^{17}$

Studies after short missions and hypokinesia of rat heart tissue showed narrowing of the small vessels, some occlusions, and endothelial projections conducive to increased permeability. ${ }^{18,31}$ Leach Huntoon and colleagues ${ }^{17}$ postulated that increased permeability of capillary membranes may be the most important mechanism for SF-induced plasma volume reduction of $>10 \%$ conducive to endothelial injuries with vicious cycles and angiotensin elevations and reduced secretion of ANP.

Too much or too little exercise will deplete $\mathrm{Mg}$ ions ${ }^{3}$ that are antioxidants as well as calcium $(\mathrm{Ca})$ blockers. ${ }^{27} \mathrm{On}$ spacecraft, it has been postulated that there may be a shift of $\mathrm{Ca}$ into the cells complicating high carbon dioxide levels. ${ }^{4}$ This may contribute to Ca overload of the mitochondria as shown in rats after $\mathrm{SF}^{31}$ Contributing to $\mathrm{SF}$ oxidative stress ${ }^{32}$ and in turn Ca overload is the necessity of $100 \%$ oxygen for 1-2 hours prior to a space walk to prevent decompression sickness. ${ }^{4} \mathrm{Mg}$ could reduce this oxidative stress, ${ }^{27,33}$ but there is no suitable subcutaneous delivery device for $\mathrm{Mg}$, since at this time a reliable subcutaneous microchip device can't be replenished. ${ }^{27}$ Invariable SF malabsorption and reduced storage sites could be responsible for significant $\mathrm{SF}$ Mg deficits $(P<0.0001)$ after shuttle missions. ${ }^{17}$ In addition to the $200 \%$ increase of plasma angiotensin after, for example, the Skylab flights of up to 84 days,${ }^{17}$ there could be the predisposition for an active intrarenal renin-angiotensin system. SF is conducive to increased angiotensin effects from both reduced plasma volume ${ }^{17}$ and ANP deficits with reduced $\mathrm{NO}^{15}$ and also from $\mathrm{Mg}$ ion deficits. Magnesium also affects the synthesis and release of ANP. ${ }^{16}$ An intrarenal renin-angiotensin system resulting from SF-reduced NO could contribute to chronic kidney disease stemming from inflammation both directly and through interaction with oxidative stress mechanisms. ${ }^{17,18,32,34,35}$ Elevated sympathetic nerve activity has been shown unequivocally in patients with renovascular hypertension, ${ }^{36}$ but until a few years ago the catecholamine levels were not thought to be elevated with SF. This concept has now been shown to have been incorrect. Christensen and colleagues, ${ }^{37}$ for example, have shown that plasma norepinephrine (NE) and plasma renin activity ${ }^{38}$ were increased even to levels above those of the seated ground-based position. Plasma NE was approximately twice the value of the supine position on the ground, predisposing those in SF to nondipping, as noted above. ${ }^{30}$ Furthermore, it was stated that the reason for this was unclear. Certainly one mechanism may be the reductions of SF Mg ion levels with, in turn, elevations of catecholamines, along with elevations of angiotensin and aldosterone $(P=0.0008)$ with ongoing vicious cycles. ${ }^{1,3,4,17,18,27,39}$ Magnesium may also provide protection against the renal damaging effects of aldosterone, predisposing the person to fibrosis. ${ }^{39-41}$

\section{Gender selection}

Pertaining to the predisposition for renovascular hypertension, young females have several clear advantages. The endothelium is not adequately repaired after the age of 30 years, ${ }^{3}$ and the cardiovascular mortality rate is six times higher in males than females under the age of 35 years. This could be related not only to estrogen's vascular advantages ${ }^{3}$ and probably to the fact that males have no physiological way of losing iron, predisposing them to oxidative stress, but also could be related to other clear advantages in females. The levels of ANP in females are approximately twice those of young men..$^{42}$ During the 438-day mission of Polyakov and after just five months in space, his cyclic guanosine monophosphate (cGMP) levels were undetectable, which supports my hypothesis. ${ }^{3,43}$ cGMP is a second messenger of both NO and ANP, and Polyakov's cGMP did not return to premission levels until three months after this mission. The cGMP-signaling pathway has been postulated as an important regulator of renal physiology. ${ }^{15}$ ANP receptors are expressed on the surface of renal endothelial cells, ${ }^{15}$ and ANP inhibits renin release and can reduce renal damage from an ischemic insult. ${ }^{38}$

Metabolic balance studies of young adults showed that with marginal intakes of $\mathrm{Mg}$, males tended to be in negative $\mathrm{Mg}$ balance whereas females remained in equilibrium. Catecholamine levels in males, in turn, are therefore higher with vicious cycles between $\mathrm{Mg}$ ion deficits and catecholamine elevations $^{39}$ (Figure 1). After SF of only 18-22 days, rats showed an increased activity of the juxtaglomerular apparatus $^{18}$ and similarly, experimental $\mathrm{Mg}$ deficiency has been shown to cause hypertrophy of this structure, resulting 


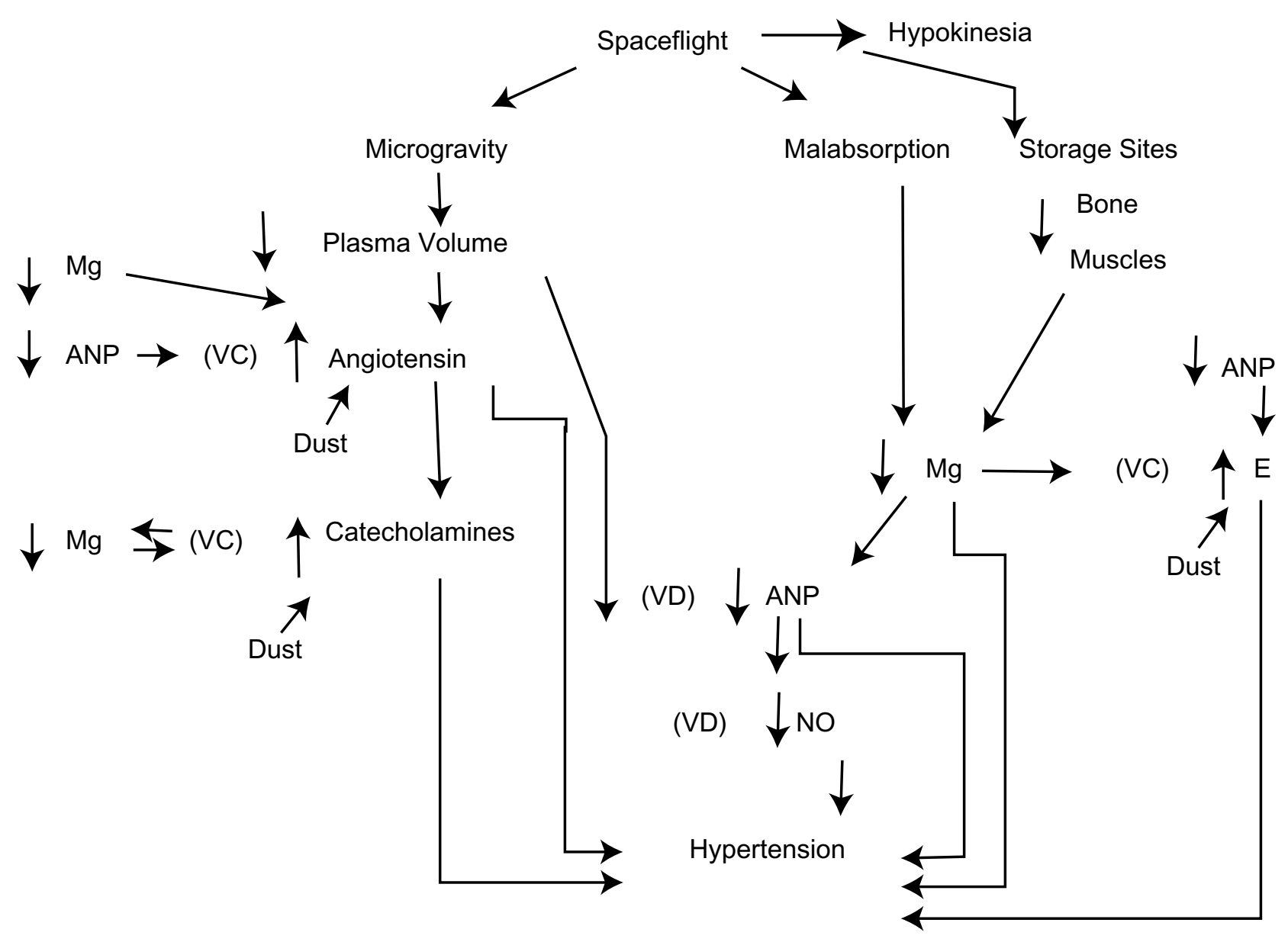

Figure I Proposed mechanisms showing how decreased atrial natriuretic peptide can cause severe hypertension secondary to dust inhalation, microgravity, and hypokinesia. Abbreviations: Catecholamines, epinephrine, norepinephrine, increased by dust; VC, vessel constriction; VD, vessel dilatation; Mg, magnesium ions; ANP, atrial natriuretic peptide; hypokinesia, decreased movement; angiotensin, angiotensin effect, increased by dust; NO, nitric oxide (endothelial derived relaxing factor); $\mathrm{E}$, endothelin, increased by dust.

in aldosterone secretion, and in turn, an increased $\mathrm{Mg}$ loss and another vicious cycle. ${ }^{27,39}$ VEGF levels are significantly higher during the formative stage (early teens) in females, although not in adulthood, ${ }^{44}$ which would enhance repair of the endothelium as well as increase the development of collateral circulation. ${ }^{28,29}$

\section{Gene therapy}

How can we offset the SF reductions in $\mathrm{cGMP}^{43}$ to maintain endothelial function by utilizing novel pharmacological compounds to prevent renal disease and in turn hypertension? How can we break self-perpetuating vicious cycles? Oxidative stress involving the kidneys and blood vessels triggers hypertension, whereas conversely hypertension has been shown to cause oxidative stress and inflammation in the kidney and cardiovascular tissue of experimental animals. ${ }^{45}$ With very long missions, gene therapy may be the only option even without consideration of renal complications. ${ }^{46}$ Gene therapy has been proposed, for example, to prevent invariable space anemia. ${ }^{7}$ This, therefore, could be of vital importance in preventing ANP deficiencies. ${ }^{6}$ There is a $10 \%$ red blood cell mass loss within one week of entering space. ${ }^{17}$ Anemia may contribute to endothelial dysfunction by reducing oxygen delivery and intensifying oxidative stress since red blood cells have important antioxidant functions. ${ }^{47}$ In addition there are SF reductions in platelets, the primary source of VEGF, which, in turn, play an important role in angiogenesis, function, and repair of the endothelium. ${ }^{27}$ With SF there are reductions of water because of reduced thirst and loss of storage sites for water and $\mathrm{Mg}$, and an impairment in red blood cell production. Therefore there is a reduction of three natural antioxidants conducive to endothelial dysfunction. $1,3,4,48,49$ Furthermore, there is no subcutaneous device available to replenish $\mathrm{Mg} .{ }^{27}$

Without the availability of pharmaceuticals for use in $\mathrm{SF}$, there is no alternative but the use of gene therapy. In addition to its use to correct invariable SF anemia, ${ }^{7}$ gene 
therapy studies have been conducted to reduce $\mathrm{BP}^{6,50,51} \mathrm{NO}$ is generated by NO synthase (NOS) enzymes and NOS gene transfer has been shown to reverse endothelial dysfunction in several diseases including hypertension and atherosclerosis. In addition NOS gene therapy has been shown to improve renal function and since NO is antifibrotic, this therapy may reduce the potential for renal fibrosis complicating aldosterone excess..$^{40,52}$ A major stumbling block, however, has been finding a suitable vector to deliver the gene to the site of action and this may require several years (possibly decades) of SF research involving vector studies with progressively wider applications..$^{53}$

A number of viruses have been developed for gene transfer but the focus has been primarily on retroviruses, adenoviruses, adeno-associated viruses, and lentiviruses. The latter are currently of great interest; they are a type of retrovirus that can infect both dividing and nondividing cells because their virus "shelf" can get through the intact membrane of the nucleus of the target cell. However because of persistent serious immune reactions with viruses, some researchers are directing their investigations to nonviral gene delivery. For example liposomal gene transfer has been investigated but there is a relatively low level of gene expression compared with that achieved from viral vectors. ${ }^{52}$

It has been emphasized ${ }^{52}$ that gene therapy has not proven to be nearly as successful as had been predicted, which may be due to only transient transfection efficiencies. In addition if the expression of NOS gene therapy is not tightly regulated to the target site, there is the potential complication of pronounced hypotension with impending shock. McCarthy and colleagues ${ }^{52}$ conclude, by stating that although thousands of patients have been treated with gene transfer therapies, reproducibility of positive results has yet to be demonstrated conclusively.

I have stressed that one of the major concerns with SF is the vulnerability of the endothelium and, therefore, research must include the correction of ANP, NO, VEGF, and red blood cell deficiencies, the latter because of its antioxidant effect; this effect is shared by $\mathrm{Mg}$ administration, ${ }^{33}$ which also has an anti-inflammatory and antifibrotic effect, and can prevent aldosterone-induced renal dysfunction (proteinuria). ${ }^{40}$ Since transfection efficiency may be temporary, ${ }^{52}$ gene therapy will have to be repeatedly reevaluated, depending upon the length of the mission. This will involve regularly scheduled diagnostic evaluation tests. How complex will these tests be and how much equipment and personnel will be required?
The gravity on the moon is $1 / 6 \mathrm{G}$ whereas Mars is $0.38 \mathrm{G}$. Investigators have argued for decades as to how much $<1 \mathrm{G}$ is tolerable. Since we have Earth genes, I believe that any fraction $<1 \mathrm{G}$ may be ultimately intolerable. There is a solution, but we are only at the threshold of a process that may require many decades of gene therapy research before we are ready to embark on very long missions or colonize other planets. Is it "our destiny to colonize" before this research is complete? Some animals that spend all their lives in caves can't adapt to the outside. Are we spared the restrictions of Nature? We share at least $80 \%$ of the same genes as rats.

\section{Conclusions}

Even though with relatively short missions (six months), the mean 24-hour BP is not elevated unless there is hypertension from inhalation of dust in the habitats without adequate protection devices, it seems reasonable to speculate that ultimately, astronauts will develop renovascular hypertension unless gene therapy is utilized. Until a suitable replenishable subcutaneous device is developed, $\mathrm{Mg}$, necessary for the synthesis as well as the release of ANP, cannot be administered. Space missions of considerable length are more likely to succeed with a female crew. In addition to ongoing pharmaceutical research, a comprehensive gene research program should begin now. Specifically gene therapy may be necessary to suppress activity of an upregulated intrarenal renin-angiotensin system.

\section{Disclosure}

The author reports no conflicts of interest in this work. No grants or other support was received. The paper was presented in part at the European Magnesium Meeting. ParisCordeliers, May 15-17, 2008. The author greatly appreciates the assistance of retired NASA archivist, Lee Saegesser, who has provided a wealth of information for several years and for the conscientious work of all four librarians at the Medical University Of Ohio in Toledo who spent a portion of three days searching through NASA publications - in vain - as to whether Irwin's extraordinary stress test data had ever been published.

\section{References}

1. Rowe WJ. The Apollo 15 space syndrome. Circulation. 1998;97:119-120.

2. Watenpaugh DE, Buckey JC, Lane LD, et al. Effects of spaceflight on human calf hemodynamics. J Appl Physiol. 2001;90:1552-1558.

3. Rowe WJ. Interplanetary travel and permanent injury to normal heart. Acta Astronaut. 1997;40:719-710, 722.

4. Rowe WJ. Moon dust may simulate vascular hazards of urban pollution. JBIS. 2007;60:133-136 
5. Higashi Y, Sasaki S, Nakagawa K, Matsuura H, Oshima T, Chayama K. Endothelial function and oxidative stress in renovascular hypertension. N Engl J Med. 2002;346:1954-1962.

6. Lin KF, Chao J, Chao L. Human atrial natriuretic peptide gene delivery reduces blood pressure in hypertensive rats. Hypertension. 1995;26(Part 1):847-853.

7. Ohi S. Developing protocols for recombinant adeno-associated virusmediated gene therapy in space. J Gravit Physiol. 2000;7:67-68.

8. Amidon GL, DeBrincat GA, Najib N. Effects of gravity on gastric emptying, intestinal transit, and drug absorption. J Clin Pharmacol. 1991;31:968-973.

9. Du J, Bayuse TM, Shah V, Putcha L. Stability of pharmaceuticals during space flight [abstract]. AAPS Pharm Sci. 2002;T3153.

10. Graebe A, Schuck EL, Lensing P, Putcha L, Derendorf H. Physiolgical, pharmacokinetic, and pharmacodynamic changes in space. J Clin Pharmacol. 2004;44:837-853.

11. Wade CE, Morey-Holton E. Alteration of renal function of rats following spaceflight. Am J Physiol. 1998;275:R1058-R1065.

12. Fritsch-Yelle JM, Charles JB, Jones MM, Wood ML. Microgravity decreases heart rate and arterial pressure in humans. $J$ Appl Physiol.1996;80:910-914.

13. Shiraishi M, Kamo T, Kamegai M, et al. Periodic structures and diurnal variation in blood pressure and heart rate in relation to microgravity on space station MIR. Biomed Pharmacother. 2004;58:S31-S34.

14. Matsukawa T, Mano T. Atrial natriuretic hormone inhibits angiotensin II-stimulated sympathetic nerve activity in humans. Am J Physiol. 1996;271(2 Pt 2):R464-R471.

15. Costa DM, Gonzalez Bosc LV, Majowicz MP, Vidal NA, Balaszczuk AM, Arranz CT. Atrial natriuretipeptide modifies arterial blood pressure through nitric oxide pathway in rats. Hypertension. 2000;35:1119-1123.

16. Wong NLM, Hu DCK, Wong EFC. Effect of dietary magnesium on atrial natriuretic peptide release. Am J Physiol. 1991;261(5 Pt 2): H1353-H357.

17. Leach Huntoon CS, Grigoriev AI, Natochin YV. American Astronaut Society. Fluid and Electrolyte Regulation in Spaceflight. (Science and Technology Series 94). San Diego, CA: Univelt; 1998.

18. Atkov OY, Bednenko VS. Hypokinesia and Weightlessness: Clinical and physiologic aspects. Madison, WI: International Universities Press; 1992. p. 1-67.

19. Neuhofer W, Pittrow D. Role of endothelin and endothelin receptor antagonists in renal disease. Eur J Clin Invest. 2006;36:78-88.

20. Liao TD, Yang XP, Liu YH, et al. Role of inflammation in the development of renal damage and dysfunction in angiotensin II-induced hypertension. Hypertension. 2008;52:256-263.

21. Dhaun N, Goddard J, Webb DJ. The endothelin system and its antagonism in chronic kidney disease. J Am Soc Nephrol. 2006;17: 943-955.

22. Pedrinelli R, Giampietro O, Carmassi F, et al. Microalbuminuria and endothelial dysfunction in essential hypertension. Lancet. 1994;344:14-18.

23. Mena-Martín FJ, Martín-Escudero JC, Simal-Blanco F, CarreteroAres JL, Arzúa-Mouronte D, Castrodeza Sanz JJ. Hortega Study Investigators. Influence of sympathetic activity on blood pressure and vascular damage evaluated by means of urinary albumin excretion. J Clin Hypertens (Greenwich). 2006;8:619-624.

24. Futrakul N, Sridama V, Futrakul P. Microalbuminuria - A biomarker of renal microvascular disease. Ren Fail. 2009;31:140-143.

25. Wang TJ, Evans JC, Meigs JB, et al. Low-grade albuminuria and the risks of hypertension and blood pressure progression. Circulation. 2005;111:1370-1376.

26. Radomski MW, Palmer RMJ, Moncada S. Endogenous nitric oxide inhibits human platelet adhesion to vascular endothelium. Lancet. 1987;2(8567):1057-1058.

27. Rowe WJ. The case for a subcutaneous magnesium product and delivery device for space missions. J Am Coll Nutr. 2004;23:525S-528S.
28. Hara A, Wada T, Furuichi K, et al. Blockade of VEGF accelerates proteinuria, via decrease in nephrin expression in rat crescentic glomerulonephritis. Kidney Int. 2006;69:1986-1995.

29. Masuda Y, Shimizu A, Mori T, et al. Vascular endothelial growth factor enhances glomerular capillary repair and accelerates resolution of experimentally induced glomerulonephritis. Am J Pathol. 2001;159:599-608.

30. Davidson MB, Hix JK, Vidt DG, Brotman DJ. Association of impaired diurnal blood pressure variation with a subsequent decline in glomerular filtration rate. Arch Intern Med. 2006;166:846-852.

31. Philpott DE, Popova IA, Kato K, Stevenson J, Miquel J, Sapp W. Morphological and biochemical examination of Cosmos 1887 rat heart tissue: Part I - Ultrastructure. FASEB J. 1990;4:73-78.

32. Stein TP. Space flight and oxidative stress. Nutrition. 2002; 18:867-871.

33. Garcia LA, Dejong SC, Martin SM, Smith RS, Buettner GR, Kerber RE. Magnesium reduces free radicals in an in vivo coronary occlusion reperfusion model. J Am Coll Cardiol. 1998;32:536-539.

34. Graciano ML, Cavaglieri Rde C, Dellê H, et al. Intrarenal reninangiotensin system is upregulated in experimental model of progressive renal disease induced by chronic inhibition of nitric oxide synthesis. J Am Soc Nephrol. 2004;15:1805-1815.

35. Campbell RC. The renin-angiotensin system: a 21 st century perspective. J Am Soc Nephrol. 2004;15:1963-1964.

36. Grassi G. Assessment of sympathetic cardiovascular drive in human hypertension. Hypertension. 2009;54:690-706.

37. Christensen NJ, Drummer C, Norsk P. Renal and sympathoadrenal responses in space. Am J Kidney Dis. 2001;38:679-683.

38. Brenner BM, Ballerman BJ, Gunning ME, Zeidel ML. Diverse biological actions of atrial natriuretic peptide. Physiol Rev. 1990;70:665-699.

39. Seelig M. Cardiovascular consequences of magnesium deficiency and loss: pathogenesis prevalence and manifestations-magnesium and chloride loss in refractory potassium repletion. Am J Cardiol. 1989;63:4G-21G.

40. Sontia B, Montezano ACI, Paravicini T, Tabet F, Touyz RM. Downregulation of renal TRPM7 and increased inflammation and fibrosis in aldosterone-infused mice: effects of magnesium. Hypertension. 2008;51:915-921.

41. Remuzzi G, Cattaneo D, Perico N. The aggravating mechanisms of aldosterone on kidney fibrosis. J Am Soc Nephrol. 2008;19:1459-1462.

42. Clark BA, Elahi D, Epstein FH. The influence of gender, age, and the menstrual cycle on plasma natriuretic peptide. J Clin Endocrin Metab. 1990;70:349-352.

43. Rossler A, Noskov V, Laszlo Z, Polyakow VV, Hinghoffer-Szalkay HG. Permanent depression of plasma cGMP during long-term space flight. Physiol Res. 2001;50:83-90.

44. Malamitsi-Puchner A, Tziotis J, Tsonou A, Protonotariou E, Sarandakou A, Creatsas G. Changes in serum levels of vascular endothelial growth factor in males and females throughout life. $J$ Soc Gynecol Investig. 2000;7:309-312.

45. Vaziri ND, Rodriguez-Iturbe B. Mechanisms of disease: oxidative stress and inflammation in the pathogenesis of hypertension. Nat Clin Pract Nephrol. 2006;2:582-593.

46. Rowe WJ. Extraordinary hypertension after a lunar mission. Am J Med. 2009;122:e1.

47. Dzieciuchowicz L, Checinski P, Krauss H. Heparin reduces oxidative stress in the postoperative period. Med Sci Monit. 2002;8: CR657-CR660.

48. Maier JAM, Malpuech-Brugère C, Zimowska W, Rayssiguier Y, Mazur A. Low magnesium promotes endothelial cell dysfunction: implications for atherosclerosis, inflammation and thrombosis. Biochim Biophys Acta. 2004;1689:13-21.

49. Weglicki WB, Phillips TM, Freedman AM, Cassidy MM, Dickens BF. Magnesium-deficiency elevates circulating levels of inflammatory cytokines and endothelin. Mol Cell Biochem. 1992;110:169-173. 
50. Lin KF, Chao L, Chao J. Prolonged reduction of high blood pressure with human nitric oxide synthase gene delivery. Hypertension. 1997;30(Part 1):307-313.

51. Schillinger KJ, Tsai SY, Taffet GE, et al. Regulatable atrial natriuretic peptide gene therapy for hypertension. Proc Natl Acad Sci U S A. 2005;102:13789-13794.
52. McCarthy HO, Coulter JA, Robson T, Hirst DG. Gene therapy via inducible nitric oxide synthase: a tool for the treatment of a diverse range of pathological conditions. J Pharm Pharmacol. 2008;60:999-1017.

53. Kohn DB, Candotti F. Gene therapy fulfilling its promise. $N$ Engl $J$ Med. 2009;360:518-521.

\section{Publish your work in this journal}

The International Journal of Nephrology and Renovascular Disease is an international, peer-reviewed open-access journal focusing on the pathophysiology of the kidney and vascular supply. Epidemiology, screening, diagnosis, and treatment interventions are covered as well as basic science, biochemical and immunological studies. The journal welcomes original

Submit your manuscript here: http://www.dovepress.com/international-journal-of-nephrology-and-renovascular-disease-journal research, clinical studies, reviews \& evaluations, expert opinion and commentary, case reports and extended reports. The manuscript management system is completely online and includes a very quick and fair peerreview system, which is all easy to use. Visit http://www.dovepress.com/ testimonials.php to read real quotes from published authors. 